\title{
ON- VS. OFF-HOURS ADMISSION OF PATIENTS WITH ST-ELEVATION ACUTE MYOCARDIAL INFARCTION UNDERGOING PERCUTANEOUS CORONARY INTERVENTIONS: DATA FROM A TERTIARY UNIVERSITY BRAZILIAN HOSPITAL
}

Clin Biomed Res. 2018;38(1):30-34

1 Faculdade de Medicina, Universidade Federal do Rio Grande do Sul (UFRGS). Porto Alegre, RS, Brasil.

2 Serviço de Cardiologia, Hospital de Clinicas de Porto Alegre. Porto Alegre, RS, Brasil.

Corresponding author: Guilherme Pinheiro Machado pinmach@hotmail.com Hospital de Clínicas de Porto Alegre Rua Ramiro Barcelos, 2350. 90035-903, Porto Alegre, RS, Brasil.

\author{
Guilherme Pinheiro Machado1, Gustavo Neves de Araujo², \\ Stéfani Mariani ${ }^{1}$, Elvis Cassol ${ }^{1}$, Felipe Homem Valle ${ }^{2}$, \\ Ana Maria Krepsky², Luiz Carlos Corsetti Bergoli², \\ Sandro Cadaval Gonçalves ${ }^{2}$, Rodrigo Wainstein ${ }^{2}$, Marco Wainstein ${ }^{1,2}$
}

\begin{abstract}
Introduction: Early reperfusion therapy is crucial in patients with ST-elevation myocardial infarction (STEMI). Off-hours hospital presentation may increase the time from pain to coronary reperfusion, and it may be responsible for increased cardiovascular outcomes. The aim of this study was to compare the effect of different times of presentation (on- and off-hours) on early mortality and major cardiovascular outcomes in patients with STEMI who underwent primary percutaneous coronary intervention $(\mathrm{PCl})$.
\end{abstract}

Methods: We have included consecutive patients with STEMI who underwent primary $\mathrm{PCl}$ between April 2011 and November 2016 in a tertiary university hospital in southern Brazil. Patients were divided into on- and off-hours admission. In-hospital and 30-day outcomes were evaluated.

Results: A total of 301 patients (57.4\%) were admitted during off-hours, and $223(42.5 \%)$ during on-hours. Baseline characteristics were well balanced between the two groups. Median door-to-balloon time was higher in the off-hours group than in the on-hours group: $75 \mathrm{~min}$ (IQR 60-95) vs. $60 \mathrm{~min}$ (IQR 50-73.7) respectively $(p<0.001)$. In-hospital mortality was similar between groups (odds ratio $[O R]=0.56 ; 95 \%$ confidence interval $[95 \% \mathrm{Cl}] 0.31-1.03 ; p=0.06)$ and at 30 -day follow-up $(\mathrm{OR}=0.2$; $95 \% \mathrm{Cl} 0.02-1.72 \mathrm{p}=0.14)$. In the matched cohort, no difference was found in the rates of in-hospital mortality $(\mathrm{OR}=2.0 ; 95 \% \mathrm{Cl} 0.75-5.32 ; \mathrm{p}=0.16)$ and 30 -day MACE $(\mathrm{OR}=0.9 ; 95 \% \mathrm{Cl} 0.49-1.66 ; \mathrm{p}=0.75)$.

Conclusions: In our center with PCl available 24/7 - without in-house staff - we did not observe any difference in patient characteristics, management, and outcomes, although a significant longer door-to-balloon time was found in patients treated during night shifts. Our results are consistent with those of other trials.

Keywords: Myocardial infarction; percutaneous coronary intervention; system delay

\section{INTRODUCTION}

Early and effective reperfusion therapy is known to be the most important component of treatment for ST-elevation myocardial infarction (STEMI), being responsible for reduction in infarct size, preservation of ventricular function, and significant decrease of morbidity and mortality. Furthermore, the benefit of any type of treatment decreases as the time to onset of symptoms increases ${ }^{1}$. While fibrinolytic therapy has complete reperfusion rates of only $50-60 \%$ of patients, this number rises to $95 \%$ of cases in percutaneous coronary intervention $(\mathrm{PCl})$. In addition, when analyzing short-term outcomes, it was found that patients 
who underwent angioplasty presented lower rates of mortality, reinfarction and stroke ${ }^{2}$.

Some studies suggest that patients with acute myocardial infarction (AMI) who arrive at the hospital during off-hours may present higher in-hospital and short-term mortality ${ }^{3-5}$. Available staff and degree of experience during off-hours can contribute to these results. However, these results are conflicting and may be influenced by a number of reasons, such as effectiveness of the health system, patient transfer time, and number of experienced centers available. Data regarding medical care in Brazil are scarce, but there is evidence that time of presentation does not relate to mortality in patients with STEMI who underwent $\mathrm{PCI}^{6,7}$.

The aim of this study was to compare the effect of different times of presentation (on- and off-hours) on 30-day mortality and major cardiovascular outcomes in patients with STEMI who underwent primary PCI at a tertiary university hospital.

\section{METHODS}

\section{Research Subjects}

This was a prospective single-center registry that included consecutive patients with STEMI who underwent primary $\mathrm{PCl}$ in a tertiary university hospital with a 24-hour primary PCI service in southern Brazil between April 2011 and December 2016. STEMI was defined as typical chest pain at rest associated with ST-segment elevation of at least $1 \mathrm{~mm}$ in two contiguous leads in the frontal plane or $2 \mathrm{~mm}$ in the horizontal plane, or typical pain at rest in patients with a new, or presumably new, left bundle-branch block. Exclusion criteria were lack of 30-day follow-up. This study was approved by the Institutional Research and Ethics Committee and informed consent was obtained from all patients.

\section{Study protocol}

Data from medical records were transferred to standardized case report forms (CRFs). Data collected included: baseline clinical characteristics, medical history, procedure characteristics, reperfusion strategy, initial and final thrombolysis in myocardial infarction (TIMI) flow grade, and discharge therapies. In-hospital and 30-day mortality rates were also recorded in the CRF. Thirty-day mortality was ascertained by telephone contact.

Blood samples were collected by venipuncture before the procedure as part of routine patient care. All patients were pre-treated with a loading dose of acetylsalicylic acid (300 mg) and clopidogrel (600 mg), and unfractionated heparin was used during the procedure $(70-100 \mathrm{Ul} / \mathrm{kg})$. Use of $\mathrm{Ilb} /$
IIla glycoprotein, aspirative thrombectomy and $\mathrm{PCI}$ technical strategies (i.e., pre-dilation, direct stent placement, post-dilation) were performed according to operator's choice. Coronary flow before and after the procedure was assessed and described according to TIMI criteria (13). Anticoagulants were suspended after the end of the procedure, and dual antiplatelet therapy was recommended for 12 months after the event. Creatinine was measured at baseline and 48-72 hours post-procedure. After hospital discharge, clinical follow-up was performed with either outpatient visit or telephone contact.

\section{Clinical Definitions}

Off-hours presentation was defined as hospital admission between 8:00 p.m. and 8:00 a.m. from Monday to Friday and weekends, and on-hours presentation was defined as hospital admission between 8:00 a.m. to 8:00 p.m. from Monday to Friday. Major adverse cardiovascular events (MACE) were defined as death from any cause, new myocardial infarction (MI), stroke, Canadian Cardiovascular Society class III/IV angina or re-hospitalization for congestive heart failure 30 days after primary $\mathrm{PCl}$. New MI was defined as recurrent chest pain with ST-segment elevation or new $Q$ waves and raise of serum biomarkers after their initial decrease. Stroke was defined as a new, sudden-onset focal neurological deficit of presumably cerebrovascular cause, irreversible (or resulting in death) and not caused by other readily identifiable causes.

\section{Statistical Analysis}

Continuous variables were expressed as mean ( \pm standard deviation) or median (interquartile range $[I Q R])$. Categorical variables were represented by relative and absolute frequencies. Prior to propensity score matching, patient groups were compared using the Student $t$ test (for normally distributed variables) or the Wilcoxon rank-sum test (for other variables) for continuous variables and the chi-square test or the Fisher exact test for categorical variables.

Propensity score matching was then performed to match the characteristics of the groups by defined variables so that the effect of a factor could be analyzed. Propensity score matching was used to create two groups using conditional logistic regression in which the dependent variable was time of admission and the explanatory variables were age, sex, diabetes mellitus, previous MI, left ventricular ejection fraction (LVEF) $<40 \%$, Killip class, and TIMI score. In the matched cohort, we determined the impact of explanatory variables on in-hospital mortality and MACE 30 days after discharge. All hypothesis tests had a two-sided 
significance level of 0.05 . All statistical analyses were conducted using IBM SPSS Statistics, version 21.

\section{RESULTS}

A total of 538 patients with STEMI who underwent primary $\mathrm{PCl}$ during the study period. Fourteen subjects were excluded due to incomplete follow-up. Therefore, 524 patients were included in the final analysis, of which $301(57.40 \%)$ were admitted during off-hours (Figure 1). Mean age was $60( \pm 12.14)$ years; moreover, $63.70 \%$ of patients were male and $24.40 \%$ had diabetes. Baseline characteristics of the study population according to time of admission are shown in Table 1. Median door-to-balloon time was higher in the off-hours group than in the on-hours group: 75 min (IQR 60-95) vs. 60 min (IQR 50-73.75) respectively $(p<0.001)$. There were no other significant differences in demographic characteristics, clinical presentation, procedural strategy, and angiographic success between groups.

Table 2 shows in-hospital outcomes according to the time of admission. There was a higher incidence of stroke in the on-hours group. There were no statistically significant differences in other outcomes, although mortality rate to be higher in the off-hours group ( $p=0.06$ ). After 30 days of follow-up, there were no statistically significant differences between the two groups (>0.05) (Table 3 ).
In the matched cohort, no difference was found in in-hospital mortality (odd ratio [OR] $=2.0 ; 95 \%$ confidence interval $[95 \% \mathrm{Cl}] 0.75-5.32 ; \mathrm{p}=0.16)$ and 30-day MACE $(\mathrm{OR}=0.9 ; 95 \% \mathrm{Cl} 0.49-1.66 ; p=0.75)$.

\section{DISCUSSION}

Time between onset of STEMI and reperfusion therapy plays a fundamental role in clinical outcomes. Therefore, current guidelines are categorical in recommending that door-to-balloon time should be

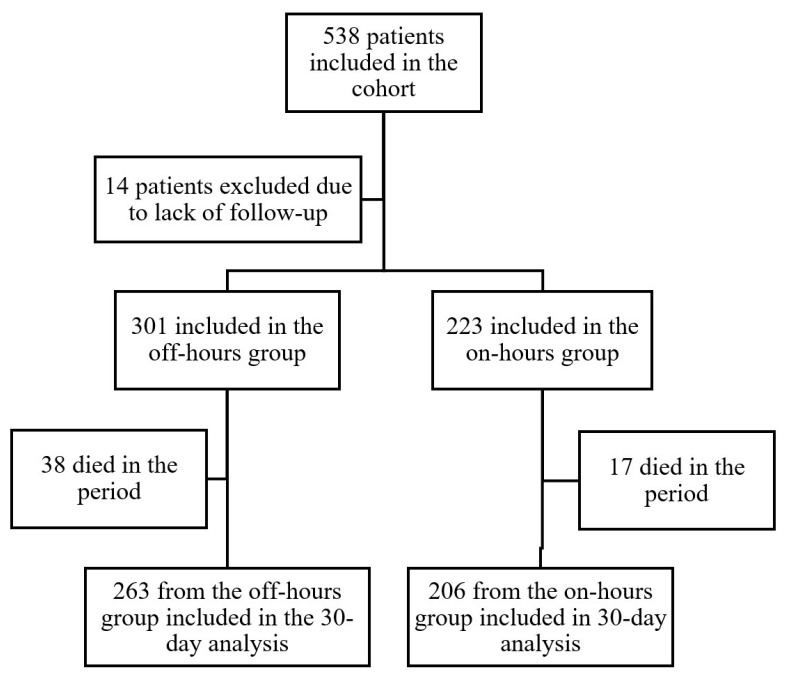

Figure 1: Flowchart of included patients.

Table 1: Baseline characteristics of the study population.

\begin{tabular}{|c|c|c|c|}
\hline & $\begin{array}{c}\text { Off-hours group } \\
n=301\end{array}$ & $\begin{array}{c}\text { On-hours group } \\
n=223\end{array}$ & p-value \\
\hline Age & $60.1( \pm 12.6)$ & $60.47( \pm 11.5)$ & 0.62 \\
\hline Male & $193(64.1 \%)$ & $144(64.6 \%)$ & 0.79 \\
\hline Caucasian & $258(85.7 \%)$ & $201(90.5 \%)$ & 0.26 \\
\hline Hypertension & $193(64.1 \%)$ & $141(63.2 \%)$ & 0.77 \\
\hline Diabetes & $72(23.9 \%)$ & $56(25.1 \%)$ & 0.80 \\
\hline Current or previous smoker & $206(68.5 \%)$ & $136(61 \%)$ & 0.14 \\
\hline CKD & $13(4.3 \%)$ & $6(2.7 \%)$ & 0.30 \\
\hline History of MI & $27(9 \%)$ & $22(9.9 \%)$ & 0.85 \\
\hline History of stroke & $17(5.6 \%)$ & $13(5.8 \%)$ & 0.98 \\
\hline COPD & $10(3.3 \%)$ & $12(5.4 \%)$ & 0.27 \\
\hline History of $\mathrm{PCl}$ or CAGB & $26(9.4 \%)$ & $25(11.8 \%)$ & 0.34 \\
\hline SBP (mmHg) & $130.48( \pm 34.6)$ & $131.15( \pm 32.9)$ & 0.68 \\
\hline Heart rate (bpm) & $79.45( \pm 18.2)$ & $78.3( \pm 18.2)$ & 0.67 \\
\hline BMI (kg/m²) & $27.26( \pm 6.6)$ & $26.73( \pm 4.9)$ & 0.40 \\
\hline TIMI risk score for STEMI & $4.24( \pm 2.7)$ & $4.03( \pm 2.5)$ & 0.40 \\
\hline Killip 3 and 4 & $43(14.3 \%)$ & $23(10.3 \%)$ & 0.93 \\
\hline Anterior MI & $144(47.8 \%)$ & $85(38.1 \%)$ & 0.05 \\
\hline Door-to-balloon & $75(60-95)$ & $60(50-73.7)$ & $>0.001$ \\
\hline Pain-to-door & $4(3-6)$ & $4(2-6)$ & 0.14 \\
\hline
\end{tabular}

Values are expressed as mean \pm standard deviation, median (interquartile range) or $\mathrm{n}(\%)$. CKD: chronic kidney disease; MI: myocardial infarction; COPD: chronic obstructive pulmonary disease; PCl: percutaneous coronary intervention; CABG: coronary artery bypass grafting; SBP: systolic blood pressure; BMI: body mass index; TIMI: thrombolysis in myocardial infarction; STEMI: ST-elevation myocardial infarction. 
Table 2: In-hospital outcomes.

\begin{tabular}{lccccc}
\hline & Off-hours group $\mathbf{n = 3 0 1}$ & On-hours group $\mathbf{n = 2 2 3}$ & OR & $\mathbf{9 5 \%} \mathbf{C l}$ & $\boldsymbol{p}$-value \\
\hline $\begin{array}{l}\text { Mortality } \\
\text { Myocardial }\end{array}$ & $38(12.7)$ & $17(7.6)$ & 0.56 & $0.31-1.03$ & 0.06 \\
infarction & $3(1.0)$ & $1(0.4)$ & 0.44 & $0.04-4.31$ & 0.47 \\
Stroke & $1(0.3)$ & $5(2.2)$ & 6.85 & $0.79-59.11$ & 0.04 \\
Stent thrombosis & $3(1.0)$ & $6(2.7)$ & 2.73 & $0.67-11.06$ & 0.14 \\
MACE & $45(15.0)$ & $24(10.8)$ & 0.68 & $0.40-1.16$ & 0.15 \\
\hline
\end{tabular}

Values are expressed as $\mathrm{n}(\%)$. OR: odds ratio; $95 \% \mathrm{Cl}$ : $95 \%$ confidence interval; MACE: major adverse cardiovascular events.

Table 3: Thirty-day outcomes.

\begin{tabular}{lccccc}
\hline & $\begin{array}{c}\text { Off-hours group } \\
\mathbf{n = 2 6 3}\end{array}$ & $\begin{array}{c}\text { On-hours group } \\
\mathbf{n = 2 0 6}\end{array}$ & OR & 95\%Cl & p-value \\
\hline Mortality & $6(2.3)$ & $1(0.5)$ & 0.20 & $0.02-1.72$ & 0.14 \\
Myocardial infarction & $2(0.8)$ & $5(2.0)$ & 3.16 & $0.60-14.46$ & 0.15 \\
Stroke & $3(1.0)$ & $1(0.5)$ & 0.41 & $0.04-4.03$ & 0.43 \\
Stent thrombosis & $5(2.2)$ & $4(1.8)$ & 0.94 & $0.26-3.75$ & 0.99 \\
Angina class III/IV & $9(3.7)$ & $14(6.9)$ & 1.87 & $0.84-4.42$ & 0.10 \\
Re-hospitalization for CHF & $8(3.0)$ & $9(4.6)$ & 1.41 & $0.53-3.74$ & 0.48 \\
MACE & $33(13.0)$ & $19(9.4)$ & 1.05 & $0.63-1.77$ & 0.83 \\
\hline
\end{tabular}

Values are expressed as $\mathrm{n}(\%)$. OR: odds ratio; $95 \% \mathrm{Cl}$ : $95 \%$ confidence interval; CHF: congestive heart failure; MACE: major adverse cardiovascular events.

less than 90 minutes $^{8}$. In our study, a delay in primary angioplasty when patients were admitted during off-hours was observed when compared to patients admitted during on-hours. In our hospital, there is no interventional cardiology team present at the hospital during night shifts or weekends, what may explain these findings. Other studies have compared on- and off-hours presentations, and found similar results ${ }^{3,4,9}$. Conversely, both clinical profiles at admission and procedural characteristics were similar between groups, and a prolonged door-to-balloon time may not be the only reason for the higher mortality in the off-hours group.

Some studies have examined the effect of off-hours admission on mortality for STEMI. A recent meta-analysis ${ }^{10}$ including 48 studies demonstrated an association between longer door-to-balloon time and short-term mortality. Although the rate of in-hospital MACE was not statistically associated with off-hours presentation in our study, mortality rate was significantly higher in the off-hours group. Magid et al. ${ }^{5}$ found that in-hospital mortality was higher in patients admitted during weekends, with a higher door-to-balloon time. Similar results regarding weekend admissions were also found by other studies $3,11,12$. However, in Brazil, two previous studies found no difference in mortality between patients with STEMI admitted on- and off-hours, yet this may be explained by the small sample sizes found in these studies ${ }^{6,7}$.
Similar to what we found in our study, most data regarding 30-day mortality do not show differences between on- and off-hours presentation ${ }^{13-17}$. Only one study found a difference in 30-day mortality and, unlike our results, lower angiographic success rates were found in patients presenting off-hours ${ }^{18}$. It is important to emphasize that most of these studies were conducted in developed countries, with a more efficient health system than we have in Brazil. These conflicting results can be influenced by a number of reasons, such as effectiveness of the health system, patient transfer time, and number of centers available.

\section{Limitations of Our Study}

This is an observational study with all the limitations inherent to this type of data analysis. We did not take into account public holidays, which could conceal differences between weekend and weekday admissions, although any effect is likely to be small. Moreover, 30-day in-hospital mortality might not capture the actual long-term difference in mortality associated with off-hour admissions for STEMI. Besides, the difference in mortality may be lost when comparing both groups due to a possible beta error. The present study is based on a single-center experience and covers only the Brazilian population, reflecting Brazilian situations in terms of geography, infrastructure, and healthcare services. Therefore, our results should be generalizable to other countries with caution, which limits external validity. 


\section{CONCLUSIONS}

In our center with $\mathrm{PCl}$ available $24 / 7$ - without in-house staff - we did not observe any difference in patient characteristics, management, and outcomes, even though a significant longer door-to-balloon time was found in patients treated during night shifts. Our results are consistent with those of other trials.

\section{Conflicts of interest}

The authors declare no conflicts of interest.

\section{REFERENCES}

1. Boersma E, Maas AC, Deckers JW, Simoons ML. Early thrombolytic treatment in acute myocardial infarction: reappraisal of the golden hour. Lancet. 1996;348(9030):771-5 PMid:8813982.

2. Keeley EC, Boura JA, Grines CL. Primary angioplasty versus intravenous thrombolytic therapy for acute myocardial infarction: a quantitative review of 23 randomised trials. Lancet. 2003;361(9351):13-20. PMid:12517460.

3. Kostis WJ, Demissie K, Marcella SW, Shao Y-H, Wilson AC, Moreyra $A E$. Weekend versus weekday admission and mortality from myocardial infarction. N Engl J Med. 2007;356(11):1099-109. PMid:17360988.

4. Krüth $P$, Zeymer $U$, Gitt $A$, Jünger $C$, Wienbergen $\mathrm{H}$, Niedermeier $\mathrm{F}$, et al. Influence of presentation at the weekend on treatment and outcome in ST-elevation myocardial infarction in hospitals with catheterization laboratories. Clin Res Cardiol. 2008;97(10):742-7. PMid:18465106.

5. Magid DJ, Wang Y, Herrin J, McNamara RL, Bradley EH, Curtis $\mathrm{JP}$, et al. Relationship between time of day, day of week, timeliness of reperfusion, and in-hospital mortality for patients with acute ST-segment elevation myocardial infarction. JAMA. 2005;294(7):803-12. PMid:16106005.

6. Cardoso CDO, De Quadros AS, Voltolini I, Azmus AD, Cardoso CR, Sebben J, et al. Angioplastia primária no infarto agudo do miocárdio: existe diferença de resultados entre as angioplastias realizadas dentro e fora do horário de rotina? Rev Bras Cardiol Invasiva. 2010;18:273-80.
7. De Albuquerque GO, Szuster E, Corrêa LCT, Goulart E, Souza AC, Sobrinho ALOA, et al. Análise dos resultados do atendimento ao paciente com infarto agudo do miocárdio com supradesnivelamento do segmento ST nos períodos diurno e noturno. Rev Bras Cardiol Invasiva. 2009;17:52-7.

8. Smith SC JR, Feldman TE, Hirshfeld JW JR, Jacobs AK, Kern MJ, King SB 3RD, et al. ACC/AHA/SCAI 2005 Guideline Update for Percutaneous Coronary Intervention --summary article: a report of the American College of Cardiology/American Heart Association Task Force on Practice Guidelines (ACC/AHA/SCAI Writing Committee to Update the 2001 Guidelines for Percutaneous Coronary Intervention). Circulation. 2006;113(1):156-75. PMid:16391169.

9. Angeja BG, Gibson CM, Chin R, Frederick PD, Every NR, Ross AM, et al. Predictors of door-toballoon delay in primary angioplasty. Am J Cardiol. 2002;89(10):1156-61. PMid:12008167.

10. Sorita A, Ahmed A, Starr SR, Thompson KM, Reed DA, Dabrh AMA, et al. Off-hour presentation and outcomes in patients with acute ischemic stroke: a systematic review and meta-analysis. Eur J Intern Med. 2014;25(4):394-400. PMid:24721584

11. Cram $P$, Hillis SL, Barnett $M$, Rosenthal GE. Effects of weekend admission and hospital teaching status on in-hospital mortality. Am J Med. 2004;117(3):151-7. PMid:15276592.

12. Isogai $T$, Yasunaga $H$, Matsui $H$, Tanaka H, Ueda T, Horiguchi H, et al. Effect of weekend admission for acute myocardial infarction on in-hospital mortality: a retrospective cohort study. Int J Cardiol. 2015;179:315-20. PMid:25464474.

13. Graham MM, Ghali WA, Southern DA Traboulsi M, Knudtson ML. Outcomes of after-hours versus regular working hours primary percutaneous coronary intervention for acute myocardial infarction. BMJ Qual Saf. 2011;20(1):60-7. PMid:21228077.

14. Hansen KW, Hvelplund A, Abildstrøm SZ, Prescott E, Madsen M, Madsen JK, et al. Prognosis and treatment in patients admitted with acute myocardial infarction on weekends and weekdays from 1997 to 2009. Int J Cardiol. 2013;168(2):1167-73. PMid:23199552.

15. Clarke MS, Wills RA, Bowman RV Zimmerman PV, Fong KM, Coory $M D$, et al. Exploratory study of the "weekend effect" for acute medical admissions to public hospitals in Queensland, Australia. Intern Med J. 2010;40(11):777-83. PMid:19811554.

16. Hong JS, Kang HC, Lee SH. Comparison of case fatality rates for acute myocardial infarction in weekday vs weekend admissions in South Korea. Circ J. 2010;74(3):496502. PMid:20075558.

17. Becker D, Soos P, Berta B, Nagy A, Fulop G, Szabo G, et al. Significance of off-hours in centralized primary percutaneous coronary intervention network. Croat Med J. 2009;50(5):47682. PMid:19839071.

18. Henriques JP, Haasdijk AP, Zijlstra F. Outcome of primary angioplasty for acute myocardial infarction during routine duty hours versus during off-hours. J Am Coll Cardiol. 2003;41(12):2138-42. PMid:12821237. 